\title{
Calculation of Assimilation Process of Non-metallic Inclusions by Slag
}

\author{
Dorota Kalisz ${ }^{\mathrm{a}, *}$ \\ ${ }^{a}$ AGH University of Science and Technology, Faculty of Foundry Engineering, Reymonta 23, 30-059 Krakow, Poland \\ *e-mail:dak@agh.edu.pl
}

Received: 2 March2016/Accepted: 7 July 2017/Published online: 28 July 2017

This article is published with open access at AGH University of Science and Technology Press

\begin{abstract}
This paper presents the results of calculating the phenomenon of the absorption of non-metallic precipitates in steel by slag. Calculations are made for the forces acting on the non-metallic particles in steel during the flow-out into the slag, depending on the particle radius and physicochemical properties of the liquid steel and slag. An analysis of the calculation results of capillary force acting on a particle in the vicinity of the steel-slag interface at changing surface energy values between the precipitates and slag shows that capillary force depends on the interfacial tension between the precipitates and slag only to a small degree.
\end{abstract}

\section{Keywords:}

non-metallic inclusions, assimilation, slag, balance of forces

\section{INTRODUCTION}

Non-metallic inclusions are assimilated by slag in the tundish and CCS crystallizer during the refining process. The following slag-phase elements participate in this process [1-15]:

- converter slag, which entered the ladle upon pouring,

- slag-forming mixtures in the form of synthetic slags or mold powders purposefully introduced to the ladle,

- steel deoxidation products, which nucleate then flow out and are assimilated by slag,

- elements of worn-out refractory lining of ladles and ceramic casing as well as the products of secondary steel oxidation, a result of contact of the open metal surface with atmosphere or oxidizing slag.

The mixing of a liquid metal bath with neutral gas or its gravity-induced flow (between metallurgical aggregates) makes the non-metallic inclusions move and flow out to the surface along with the steel. Steel in the tundish moves up to the surface or parallel to it, and the non-metallic inclusions follow the same direction. The inclusions are formed in the crystallizer as a consequence of the segregation of liquid steel components at the crystallization front. A number of processes take place there: the inclusions are repelled or absorbed by the crystallization front, and at the same time, some of the particles flow out and are assimilated by the crytallizer slag $[1-7,9,11-12,15]$.

\section{PHYSICOCHEMICAL PARAMETERS DETERMINING ASSIMILATION OF PARTICLES BY SLAG}

When a non-metallic particle is close to the liquid steel-slag interface, then the following effects may take place (depending on the physicochemical properties of the analyzed system) $[1-7,9,11-12,15]$ :

- non-metallic inclusions are assimilated by slag,

- non-metallic inclusions do not penetrate the liquid steel-slag interface,

- non-metallic inclusion oscillate around the interface to finally stay in the liquid steel.

The assimilation of non-metallic particles by slag is determined by such parameters as:

- viscosity of slag,

- density of non-metallic inclusion and of slag,

- interfacial tension:

- non-metallic inclusion/slag $\sigma_{I S^{\prime}}$

- non-metallic inclusion/metal $\sigma_{I M}$,

- metal-slag $\sigma_{M S^{*}}$

Based on interfacial tension values, the contact angle $\theta$ can be calculated $[1,9]$ :

$$
\cos \theta=\frac{\sigma_{I M} \sigma_{I S}}{\sigma_{M S}}
$$

If $\cos \theta<0$, then liquid steel wets the solid non-metallic inclusion; if $\cos \theta>0$, otherwise. 
The optimum conditions of the assimilation of solid particles of an oxide (e.g., $\mathrm{Al}_{2} \mathrm{O}_{3}$ ) are the following:

- high value of $\cos \theta$, which is typical of the low viscosity and low wettability of steel,

- big non-metallic particles are assimilated by slag more easily,

- big non-metallic inclusions oscillate more easily and, thus, are entrained by the liquid steel.

Inclusion particles approach the liquid steel-slag interface at a rate that depends on two factors:

- outflow velocity (from Stokes law),

- velocity resulting from entrainment by the liquid steel flow.

The process of non-metallic particle assimilation by slag consists of three stages:

- outflow of inclusions at the liquid steel-slag interface,

- penetration of a particle of non-metallic inclusion through the interface,

- solving of an inclusion in liquid slag.

\section{BALANCE OF FORCES ACTING ON NON-METALLIC PARTICLE}

A system of forces is acting on a particle: gravity and capillary forces (which are oriented downward) and also buoyancy (taking the opposite direction). The buoyancy depends on the position of the inclusion particle against the steel-slag interface. This position is determined by coordinate $Z$, which is equal to zero, when the particle touches a point of the interface. For a particle adsorbed by slag, $Z$ assumes positive values $[1,9]$.

\section{Buoyancy force}

$$
\begin{gathered}
F_{B}=\frac{4}{3} \cdot \pi \cdot R^{3} \cdot\left(\Delta_{b} \cdot \rho_{S}-\rho_{I}\right) \cdot g \\
\Delta_{b}=\frac{1}{4} \cdot\left(\frac{\rho_{M}}{\rho_{S}}-1\right) \cdot\left(\frac{Z}{R}\right)^{3}-\frac{4}{3} \cdot\left(\frac{\rho_{M}}{\rho_{S}}-1\right) \cdot\left(\frac{Z}{R}\right)^{2}+\frac{\rho_{M}}{\rho_{S}}
\end{gathered}
$$

Parameter $\Delta_{b}$ accounts for the position of the inclusion particle both in the steel and slag at the same time [1].

\section{Capillary force}

$$
F_{\sigma}=(-2 \cdot \pi \cdot R+2 \cdot \pi \cdot Z) \cdot \sigma_{M S}+2 \cdot \pi \cdot R \cdot \sigma_{I S}-2 \cdot \pi \cdot R \cdot \sigma_{I M}
$$

Parameter $F_{\sigma}$ results from the cooperation of three forces evoked by interfacial tension. Gradually, as the particle moves vertically, the force changes its sign. Usually, $\sigma_{I M} \geq \sigma_{I S} \sigma_{W M} \geq \sigma_{W S}$, and then the particle is expelled by the metal to the slag. After exceeding a certain value of the surface wettability ratio by slag and metal, the capillary force starts acting in the opposite direction, counteracting the movement of the particle towards the slag. The value of the capillary force depends on the chemical composition of the inclusion, steel, and slag [1].

\section{Viscous drag force}

$$
F_{V I S}=6 \cdot \pi \cdot R \cdot \eta_{S} \cdot B \cdot \frac{d Z}{d T}
$$

Coefficient B defines the influence of the viscous drag force in the steel and slag.

$$
B=1 \text { for } \frac{Z}{R} \geq 1
$$

For

$$
B=\left(\frac{\eta_{M}}{\eta_{s}}-1\right) \cdot\left(\frac{Z}{R}\right)^{2}-2 \cdot\left(\frac{\eta_{M}}{\eta_{s}}-1\right) \cdot\left(\frac{Z}{R}\right)+\frac{\eta_{M}}{\eta_{s}}
$$

As a result of the operation of these forces, the particle remains in the lowest layer of the slag, where it can be dissolved partially or completely, or it may be moved back to the metal and entrained by the steel flow. A necessary condition for an inclusion to penetrate the slag is the appropriate energy resulting from the outflow velocity $[1,9]$.

When the distance between the particle and interface is small, a thin metal film is assumed to exist through which the particle has to pass to be assimilated by the slag. Consequently, this elongates the time of the presence of the particle in this area. The existence of an interfacial metal film depends on the hydrodynamics of flow, characterized by the Reynolds number [2]:

$$
R e=\frac{U \cdot d_{p} \cdot \rho_{m}}{\eta_{M}}
$$

where:

$$
\begin{aligned}
& U-\text { elocity of particle vs. surface, } \mathrm{m} / \mathrm{s} ; \\
& d_{p}-\text { diameter of inclusion particle, } \mathrm{m} ; \\
& \rho_{m}-\text { density of metal, } \mathrm{kg} / \mathrm{m}^{3} \\
& \eta_{M}-\text { dynamic viscosity, } \mathrm{kg} / \mathrm{m} \cdot \mathrm{s} .
\end{aligned}
$$

According to [2], the interfacial metal film is formed only when $R e>1$. For low values of the Reynolds number, the interfacial metal film is not formed, and the inclusion particle has direct contact with the slag surface. Partial exceeding of the interface by the particle does not suffice to trigger out its assimilation. After the particle passes through the interface, the surface energy changes with the change of the inclusion-slag, inclusion-metal, and steel-metal interface. The way in which the surface energy changes with the movement of the particle through the interface has been illustrated with the equation below:

$$
\begin{aligned}
E= & -\pi \cdot\left(2 \cdot R \cdot Z-Z^{2}\right) \cdot \sigma_{M S}+2 \cdot \pi \cdot R \cdot Z \cdot \sigma_{I S}+ \\
& +2 \cdot \pi \cdot R \cdot(2 \cdot R-Z) \cdot \sigma_{I M}
\end{aligned}
$$


Explanations to formula (9):

$R$ - radius of inclusion particle, $\mathrm{m}^{3}$;

$Z$ - vertical coordinate;

$\sigma_{M S}-$ metal-slag interfacial tension, $\mathrm{J} / \mathrm{m}^{2}$;

$\sigma_{I S}$ - inclusion-slag interfacial tension, $\mathrm{J} / \mathrm{m}^{2}$;

$\sigma_{I M}$ - inclusion-metal interfacial tension, $\mathrm{J} / \mathrm{m}^{2}$.

Hence, the conclusion that a repulsive force exists, which counteracts the assimilation of particles by the slag.

\section{Repulsive force}

$$
F_{R}=\frac{d E}{d Z}=2 \cdot \pi \cdot R \cdot \sigma_{M S} \cdot\left(\frac{Z}{R}-1-\cos \theta\right)
$$

\section{CALCULATION OF FORCES ACTING ON NON-METALLIC PARTICLES}

The following assumptions were made to calculate forces acting on the non-metallic particles near the liquid steel-slag interface:

$\rho_{M}-$ density of steel $7000 \mathrm{~kg} / \mathrm{m}^{3}$;

$\rho_{I}-$ density of inclusion $\left(\mathrm{Al}_{2} \mathrm{O}_{3}\right) 3990 \mathrm{~kg} / \mathrm{m}^{3}$;

$\rho_{S}-$ density of slag $2750 \mathrm{~kg} / \mathrm{m}^{3}$;

$\eta_{M}$ - viscosity of steel $0.006 \mathrm{~Pa}$ 's;

$\eta_{S}$ - viscosity of slag 0.1 Pa's;

$\sigma_{M S}$ - steel-slag interfacial tension $1.2 \mathrm{~N} / \mathrm{m}$;

$\sigma_{I M}$ - inclusion-steel interfacial tension $1.5 \mathrm{~N} / \mathrm{m}$;

$\sigma_{I S}-$ slag-inclusion interfacial tension $0.1 \mathrm{~N} / \mathrm{m}$.

Figures 1 and 2 illustrate the calculated outflow velocity of a spherical non-metallic particle and Reynolds number (9) as a function of the inclusion's radius.

Figures 3 and 4 represent the results of calculating capillary force $F_{\sigma}$ and buoyancy force $F_{B}$ for various positions (determined by coordinate $Z$ ) of a spherical non-metallic particle for inclusion radius $r=0.0001 \mathrm{~m}$.

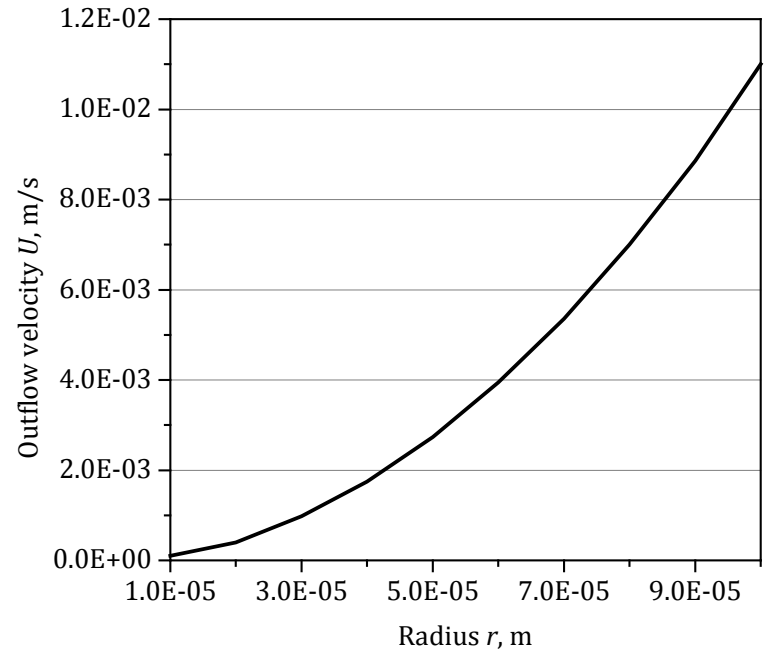

Fig. 1. Calculated outflow velocity of a non-metallic particle $\left(\mathrm{Al}_{2} \mathrm{O}_{3}\right)$ depending on radius of inclusion

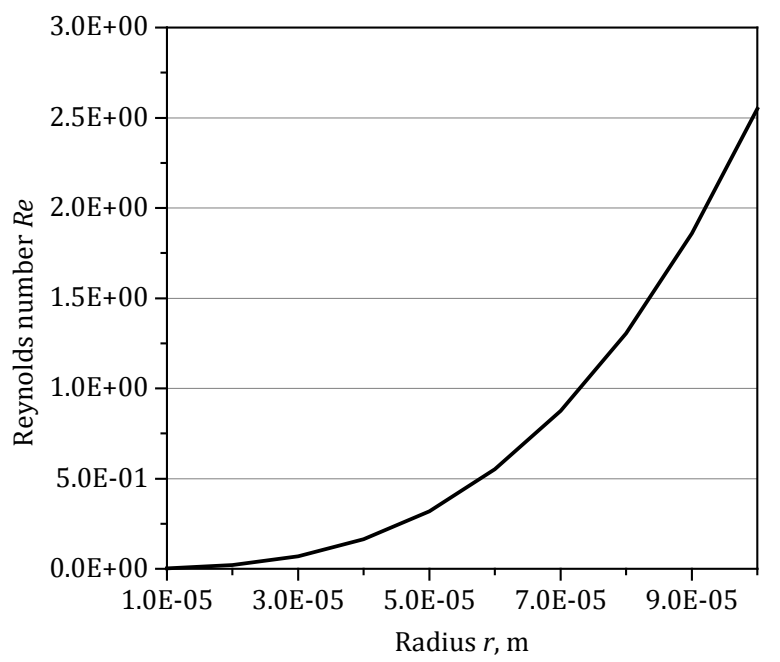

Fig. 2. Calculated Reynolds number depending on radius of inclusion

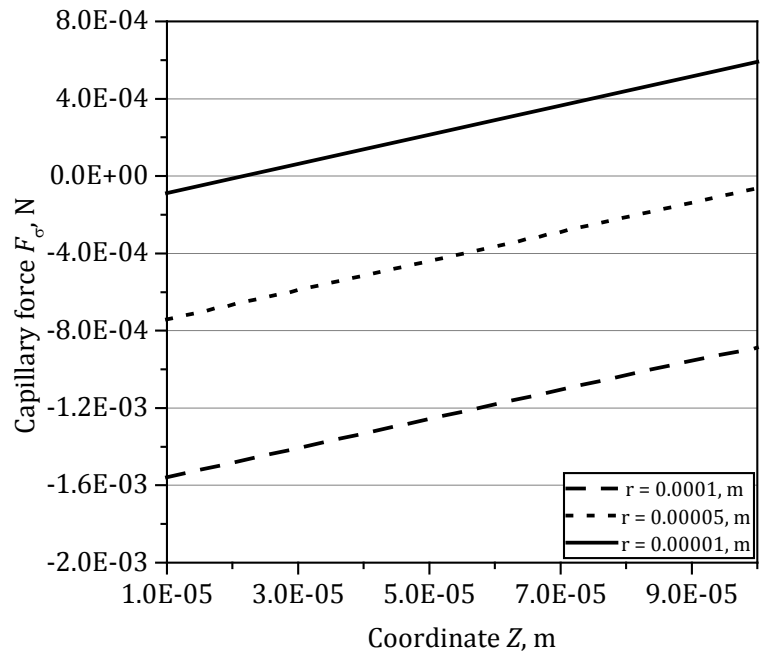

Fig. 3. Calculated capillary force $F_{\sigma}$ acting on non-metallic particle depending on coordinate $Z$ for inclusion particle of radius $r=0.0001 \mathrm{~m}$

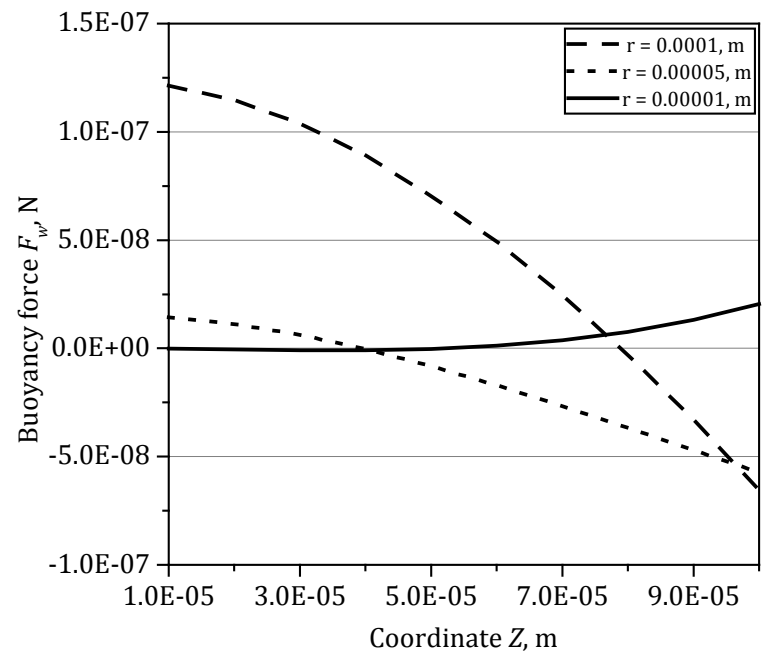

Fig. 4. Calculated buoyancy force $F_{B}$ acting on non-metallic particle depending on coordinate $Z$ for inclusion particle of radius $r=0.0001 \mathrm{~m}$ 
The results of calculating the capillary force acting on a non-metallic particle in the vicinity of the liquid steel-slag interface and the inclusion's position are presented in Figure 5 (for particles $r=100 \mu \mathrm{m}$ ) and Figure $6(r=10 \mu \mathrm{m})$.

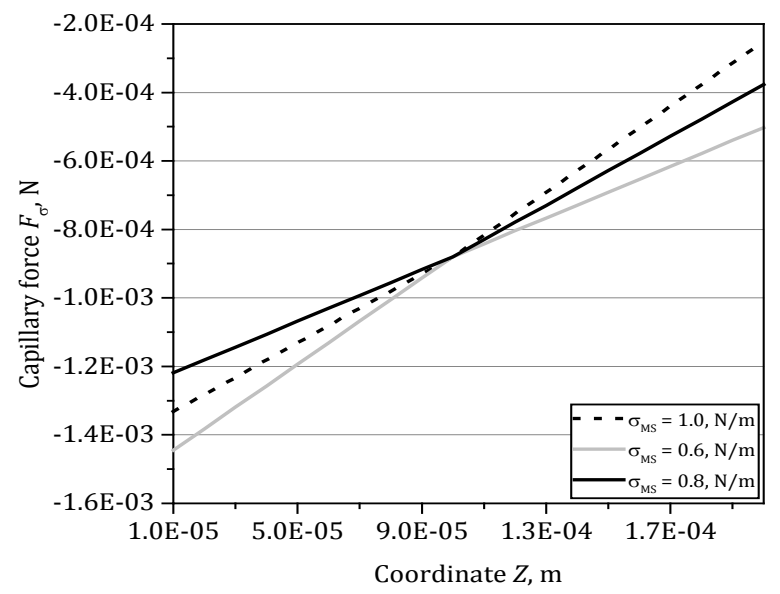

Fig. 5. Calculated capillary force $F_{\sigma}$ acting on inclusion particle of radius $r=0.0001 \mathrm{~m}$ in vicinity of interfaces for surface energy values: $\sigma_{I S}=0.05 \mathrm{~N} / \mathrm{m}, \sigma_{I S}=0.1 \mathrm{~N} / \mathrm{m}, \sigma_{I S}=0.15 \mathrm{~N} / \mathrm{m}$, and $\sigma_{I S}=0.2 \mathrm{~N} / \mathrm{m}$ against coordinate $Z$

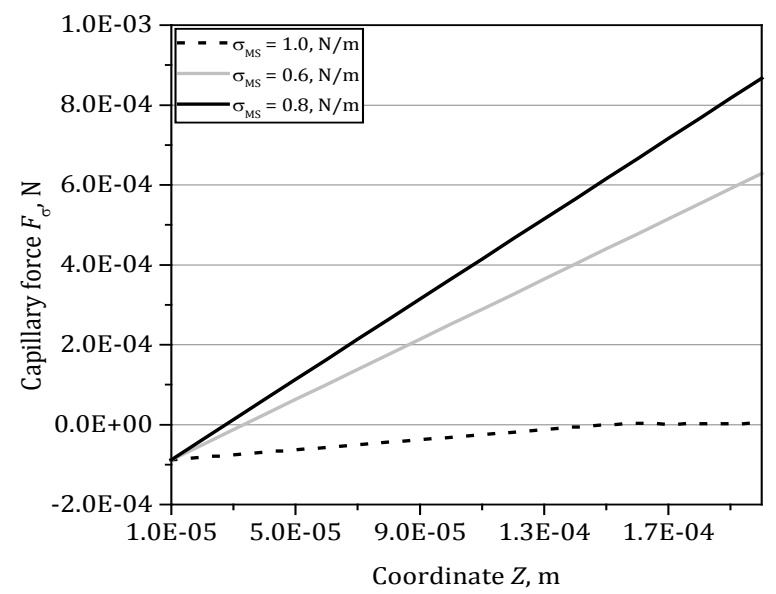

Fig. 6. Calculated capillary force $F_{\sigma}$ acting on inclusion particle of radius $r=0.0001 \mathrm{~m}$ in vicinity of interfaces for surface energy: $\sigma_{M S}=1.0 \mathrm{~N} / \mathrm{m}, \sigma_{M S}=0.8 \mathrm{~N} / \mathrm{m}$, and $\sigma_{M S}=0.6 \mathrm{~N} / \mathrm{m}$ against coordinate $Z$

The simulations were made for various values of surface energy on the liquid steel and slag contact at a constant energy of the inclusion-slag and inclusion-liquid steel interfacial tension $\sigma_{I M}=1.5 \mathrm{~N} / \mathrm{m}$, slag-inclusion interfacial tension $\sigma_{I S}=0.1 \mathrm{~N} / \mathrm{m}$, and three various values of surface energy on the liquid steel and slag contact:

- variant $1: \sigma_{M S}=0.8 \mathrm{~N} / \mathrm{m}$,

- variant 2: $\sigma_{M S}=0.6 \mathrm{~N} / \mathrm{m}$,

- variant 3: $\sigma_{M S}=1.0 \mathrm{~N} / \mathrm{m}$.

Figure 7 illustrates the calculated values of capillary force $F_{\sigma}$ acting on a non-metallic particle of radius $r=0.0001 \mathrm{~m}$ depending on the particle's positions at various surface energy values between the inclusion and slag $\sigma_{w S}$ and at the constant values of $\sigma_{M S}=1.2 \mathrm{~N} / \mathrm{m}$ and $\sigma_{I M}=1.5 \mathrm{~N} / \mathrm{m}$.

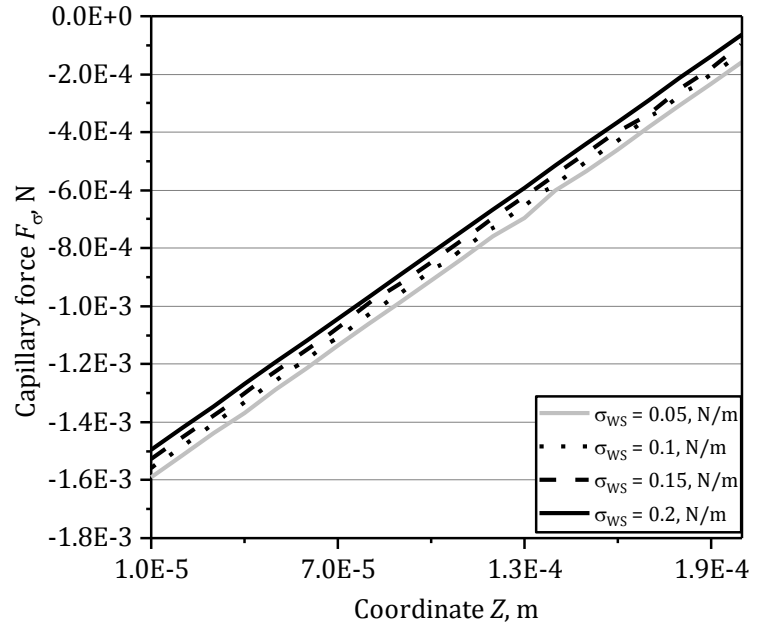

Fig. 7. Calculated capillary force $F_{\sigma}$ acting on inclusion particle of radius $r=0.00001 \mathrm{~m}$ in vicinity of interfaces for surface energy: $\sigma_{M S}=1.0 \mathrm{~N} / \mathrm{m}, \sigma_{M S}=0.8 \mathrm{~N} / \mathrm{m}$, and $\sigma_{M S}=0.6 \mathrm{~N} / \mathrm{m}$ against coordinate $Z$

\section{CONCLUSIONS}

An analysis of calculating the outflow velocity of a non-metallic inclusion $U$ reveals that the larger particles flow out faster. The aggregation of particles in bigger groups enhances the process of their removal from steel, thus increasing the metallurgical purity and quality of the ready products. Simultaneously, the size of the inclusions has an influence on the Reynolds number. Low Reynolds values (at which metal does not have any boundary film separating it from slag) are obtained for $\mathrm{Al}_{2} \mathrm{O}_{3}$ particles of less than a $0.00007 \mathrm{~m}$ radius, and for the assumed viscosity and density of liquid steel values. The main forces acting on the non-metallic particle (i.e., capillary force and buoyancy) depend on the position and size of the particle. The value of the capillary force acting on the particle increases as the inclusion approaches the interface; the change of steel-slag surface energy does not change this trend. An analysis of the calculation results of capillary force acting on a particle in the vicinity of the steel-slag interface at changing surface energy values between the inclusion and slag shows that capillary force depends on the interfacial tension between the inclusion and slag only to a small degree.

\section{Acknowledgements}

The research was performed within the AGH UST project 11.11.170.318.14

\section{REFERENCES}

[1] Bouris D., Bergeles G. (1998). Investigations of Inclusion Re-entrainment from the Steel-Slag Interface. Metallurgical and Materials Transactions B, 29B, 641-649.

[2] Strandh J., Nakajima K., Eriksson R., Jonsson P. (2005). A mathematical model to study liquid inclusion behavior at the steel-slag interface. ISIJ International, 45(12), 1838-1847.

[3] Sangguan D., Ahuja S., Stefanescu D.M. (1992). An analytical model for the interaction between an insoluble particle and an advancing solid/liquid interface. Metallurgical and Materials Transactions A, 23A, 669-680. 
[4] Stefanescu, D.M., Dhindaw, B.K., Kacar, S.A., Moitra A. (1988). Behavior of ceramic particles at the solid - liquid metal interface in metal matrix composites. Metallurgical and Materials Transactions A., 11(9A), 2847-2855.

[5] Mukai K., Zeze M. (2003). Motion of fine particles under interfacial tension gradient in relation to continuous casting process. Steel Research, 74(3), 131-138.

[6] Shibata H., Yoshinaga H., Yin S., Emi T., Suzuki M. (1998). Insitu observation of engulfment and pushing of nonmetallic inclusions in steel melt by advancing melt/solid interface. ISIJ International, 38, 149-156.

[7] Stefanescu D.M., Phalnikar R.V., Pang H., Ahuja S., Dhindaw B.K. (1995). A coupled force field - thermal field analytical model for the evaluation of the critical velocity for particle engulfment. ISIJ International, 35, 700-707.

[8] Slovic Z., Nedejkovic L.J., Raić K., Odanović Z. (2012). Relationship between the common optical basisity models and sulphide capicities of $\mathrm{CaO}-\mathrm{Al}_{2} \mathrm{O}_{3}-\mathrm{SiO}_{2}-\mathrm{MgO}$ slag. Kovove Materialy, 50(3), 185-192.

[9] Kalisz D. (2013). Termodynamiczna charakterystyka powstawania fazy niemetalicznej w ciekłej stali. Kraków: Akapit.
[10] Kalandyk B., Wojtal W. (2011). Effects of steel - applied for large-dimension castings for the power engineering - refining in the ladle - furnace. Archives of Metallurgy and Materials, 58(3), 779-783.

[11] Kalisz D. (2014). Interaction of non-metallic inclusion particles with advancing solidification front. Archives of Metallurgy and Materials, 59(2), 493-500.

[12] Żak P.L., Kalisz D., Lelito J., Szucki M., Gracz B., Suchy J.S. (2015). Modeling of non-metallic particles motion process in foundry alloys. Metallurgija, 54(2), 357-360.

[13] Iwanciw J., Podorska D., Wypartowicz J. (2011). Simulation of oxygen and nitro gen removal from steel by means of titanium and aluminium. Archives of Metallurgy and Materials, 56(3), 635-644.

[14] Moser Z., Gąsior A., Dębski J., Pstruś J. (2012). Surdat 2, Data-base of Physicochemical Proporties of Selected Solders. Krakow: Polish Academy of Sciences, OREKOP.

[15] Szucki M., Kalisz D., Lelito J., Żak P.L., Suchy J.S., Krajewski K.W. (2015). Modelling of the crystallization front - particles interactions in $\mathrm{ZnAl} /(\mathrm{SiC})_{\mathrm{p}}$ composites. Metallurgija, 54(2), 375-378. 